\title{
Smart garbage level Monitoring using iot
}

Sk. Khaja Mastan, M. Raja

\begin{abstract}
In latest few years we can examine quick increase in urban improvement plans, the concept of smart cities. While the concept comes up for Smart cities there's a requirement for Smart waste management. The important aim of Garbage tracking system is for the Smart buildings, Colleges, Hospitals and Bus stands to hold cleanliness. The Garbage tracking device theory is an improvement of regular dustbin by increases it to be smart using IR sensors. Garbage monitoring device is a new Technology of implementation which makes a regular dustbin smart using ultrasonic sensors for rubbish level monitoring and detection, it video display units and sends message to the concern department committee updating the status of the bin the usage of GSM modem when bin is
\end{abstract}

Key Words: IOT smart garbage level monitoring, Internet of things (IOT).

\section{INTRODUCTION}

Garbage! In our day to day life, we see many pictures regarding garbage packing containers being overfull and all it smells out. This leads us to growth numerous number of illnesses as uncountable number of bugs and mosquitoes mate on it. A main trouble in clever cities is stable waste management, not best in India and lots of greater countries within the world. This project helps us to offer the most efficient approaches to keep our society easy and green. Many range of clever cities, big numbers of responsibilities is likewise required to be fulfilled. The main vital need for a clever way of lifestyles is starts with cleanliness and cleanliness begins with smart dustbins. The right dispatch of waste is possible handiest when the dustbins are located well and collected properly The main trouble associated with present waste management machine is, most of the cities are damaging fame of dustbins via fallacious maintenance. So, by means of using this method we will send information to the concern persons and show forums are arranged inside the concern offices. The complete development of waste throughout the whole city can be traced and thus may be monitored by way of a single gadget efficiently. Then this system can show to be a revolution for the complete waste management system for future use in smart towns.
Revised Manuscript Received on February 05, 2020.

* Correspondence Author

Sk,Khaja Mastan*, pursuing Final year, ECE Department, Saveetha School of Engineering, Kuthambakkam, Tamil Nadu

M.RAJA, Assistant professor, ECE Department, Saveetha School of Engineering, Kuthambakkam, Tamil Nadu smoussa@cud.ac.ae

(C) The Authors. Published by Blue Eyes Intelligence Engineering and Sciences Publication (BEIESP). This is an open access article under the CC BY-NC-ND license (http://creativecommons.org/licenses/by-nc-nd/4.0/)

\section{EXISTING SYSTEM}

\section{GSM based Garbage Monitoring System}

In our daily routine life, regularly we look at that the garbage boxes or dirt bins are located at public places inside the many cities are overflow due to boom within the waste in our day after day life.

It creates harmful circumstance for the peoples and creates depressing odor around the surroundings this leads in spreading a few life-threatening sicknesses and human disorder, to keep away from any such attenuation we are making plans to design "GSM based garbage monitoring gadget for building smart cities" In proposed machine there are multiple dustbins positioned for the duration of the metropolis or the campus, these dustbins are furnished with low cost embedded device which helps in tracing level of rubbish bins and an specific ID will be provided for specific dustbin inside the metropolis. From this way it is easy to discover which rubbish bin is filled. When the extent reaches threshold limits, the tool will assist to transmit the level alongside with specific ID furnished for each dustbin. These details can be obtained by the priority government from their region with the assist of GSM/GPRS and a direct action may be made to easy the dustbins and to hold cleanliness via the whole city by the use of clever dustbin concept.

\section{PROPOSED SYSTEM}

\section{Ultrasonic sensor:}

We use ultrasonic sensor to monitor the level of garbage, it is based on sound signal so it increase our process accuracy.

\section{Adriano Mega 2560:}

This unit is brain of project it get signal from ultrasonic sensor, calculate the garbage bin status. If the bin is full it sends the SMS via GSM modem to the corresponding person and also update the data to server via PC. Here we have two serial communication device (GSM modem \& PC) so only we choose Arduino Mega 2560.

\section{GSM modem:}

It is used to send the SMS to the corresponding person, it is done with the help of AT commands.

PC:

Through PC only Adriano Mega 2560 update the status of the Garbage bin to the server, for this we use Python Programming

Published By:

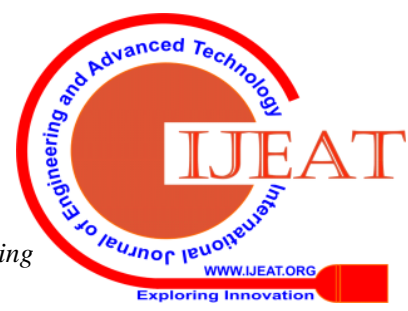




\section{REQUIREMENTS}

HARDWARE REQUIREMENTS:

$>$ ARDUINO MEGA

$>$ ULTRASONIC SENSOR

$>$ GSM MODEM

$>\mathrm{PC}$

SOFTWARE REQUIREMENTS:

$>$ ARDUINO IDE - FOR ARDUINO UNO (FOR PYTHON PROGRAM)

BLOCK DIAGRAM:

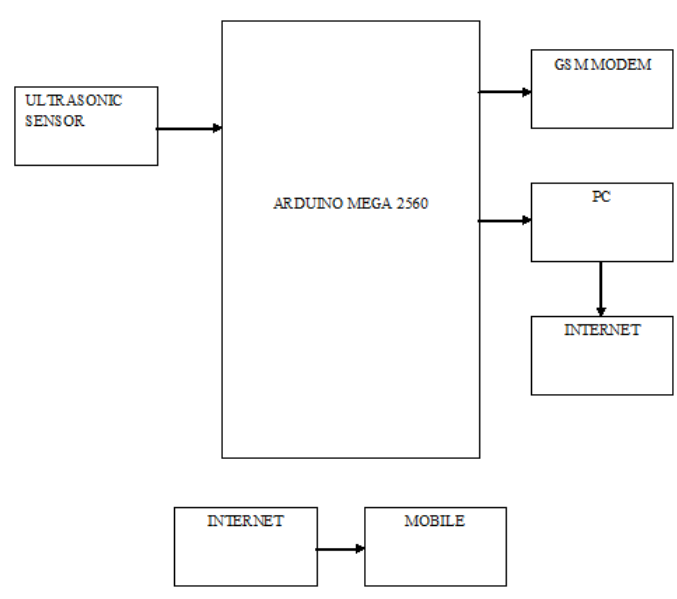

\section{V.ISSUES}

From previous couple of years, net changed into recognized to be a massive mass that we are able to gather statistics from. Embedding mobile transceivers to normal gadgets and gadgets enabled to new varieties of bi-directional communiqué among one character to another person, and people with That pattern is referred to as Internet of Things, it changed into primarily added in 1998 by Kevin Ashton, has obtained recently greater attention in the academia and industry, and this would add a brand new measurement to the world of Information and conversation technology from latest survey on While that pattern is developing and have excessive positive effect on many components of Our livelihood, challenging troubles come about, that need to be taken into consideration and adopt to remedy particular problem. The central issues are insuring safety and privacy of users and their facts. One extra issue is fully accomplishing smartness for interconnected gadgets by means of authorize their interaction. Exchanging information and autonomous behavior is the key for reaching the latter. IOT has various meanings from numerous perspectives, anyhow, they all flip round around "things" mostly, gathering, exchanging and communicating information with every other's and with people via "internet". It facilitates in decision making and automating almost the whole lot round us within the world.
$>$ PYTHON3.7 \& LICLIPSE IDE - FOR PC

The abstraction of Internet of things (IOT) was introduced by the extension of the widely used global network known as the internet. Along with the deployment of everywhere computing and mobiles in smart objects which brings new opportunities for the creation of innovative solutions to various aspects in day to day life. The main aim of IoT that to create a network of objects that can communicate, communicate and cooperate together to reach a common goal IOT gadgets can increase our day by day lives, as each tool stops acting as a single tool and become part of a whole full connected system. This helps us with the resulting data to be explored for better decision making, tracking our businesses and monitoring our properties while we are far away from them.

\section{EVOLUTION OF INTERNET OF THINGS:}

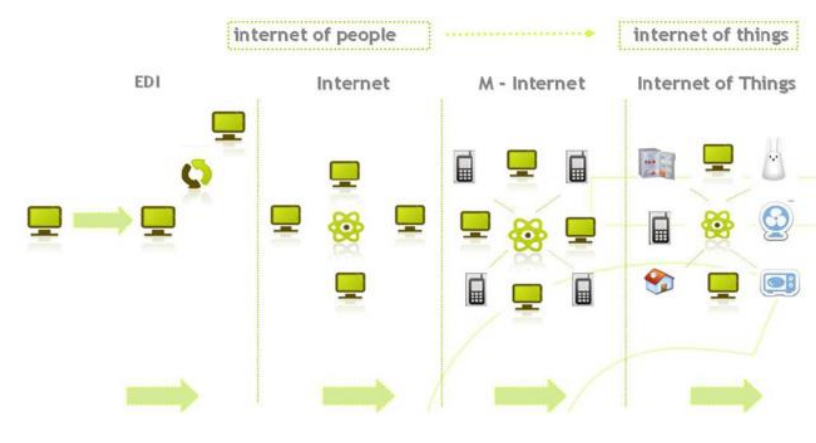

EDI:

Electronic records interchange (EDI) is the idea of corporations electronically communicating information that changed into time-honored communicated on paper, for think buying orders and invoices. Technical standards for EDI exist to permit occasions transacting such gadgets while not having to make precise arrangements.

INTERNET:

The Internet is the universal machine of interconnected computer networks that use the Internet protocol suite (TCP/IP) to hyperlink devices everywhere in universe. It is a network that includes private, public, academic, business, and authorities community of nearby to worldwide scope, related by way of a extensive array of electronic, wireless, and optical networking The Internet contains a huge quantity of information assets and services, inclusive of the inter-related hypertext files and programs of the World Wide Web (WWW), Data transferring, electronic mail (Email), telephony, and report.

\section{M-INTERNET:}

The mobile web, is likewise known to be mobile internet, refers to browser-based Internet services retrieve from handheld cellular devices, consisting of smartphones or feature phones, through a mobile or thru other wi-fi network.

IOT:

As the pattern of IOT is growing, it is stepping into every aspect of our day to day lives.

Published By: 
This leads to an easier life through wider range of applications, such as electronic health care solutions And Smart city concept. The concept of Smart city aims to making a better use of resources, increasing services quality oared to the citizens, and reducing costs of the public administrations. One more application is home automation.

\section{APPLICATIONS OF IOT:}

VI.CONCLUSION

From above mentioned data we conclude that many smart cities are using concept of "SMART GARBAGE LEVEL MONITORING USING IOT" to reduce many disease caused by due to overflow of bins in many areas and make particular area in healthy state. With help of IR Sensors we can detect how much amount of bin is filled. The four IR Sensors are placed in different places of bin to monitor level of dust. The main cause for many disease is due to overflow of garbage in many areas. For controlling spreading of disease the above mentioned concept is best way to maintain healthy conditions in cities. By this process we can make our city clean and resolve many issues caused by bacteria present in garbage, and also many of animals will eat over flow of garbage in cities such as plastic, unhygienic food etc... with help of IOT system presenting in bin it automatically detects the garbage in bin. When four IR Sensors giving bugler sound then automatically a message will be delivered to near municipal office with help of GSM/GPRS. Then particular people come and collect the garbage from bin to dump in dump yards. From this smart system we can maintain cleanness and healthy relationships in particular areas.

\section{TEST CASES AND RESULTS}

We can monitor level of garbage in bin with help of ultra sonic sensor. We place Ultrasonic sensor at different places in Bin when both sensors gives alert then with help of GSM/GPRS it can send alert to particular person.

1) When bin is half filled then First level of sensor gives alert (0-50\%).

2) When bin is completely filled then Second level of sensor gives alert (51-95\%).

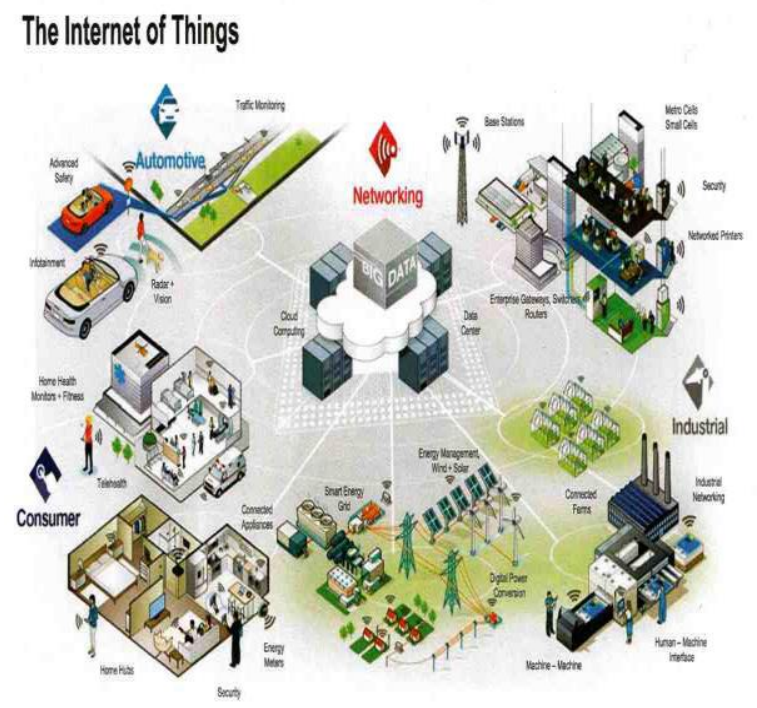

When both the sensors give alert automatically it sends message to particular person with help of GPS/GPRS.

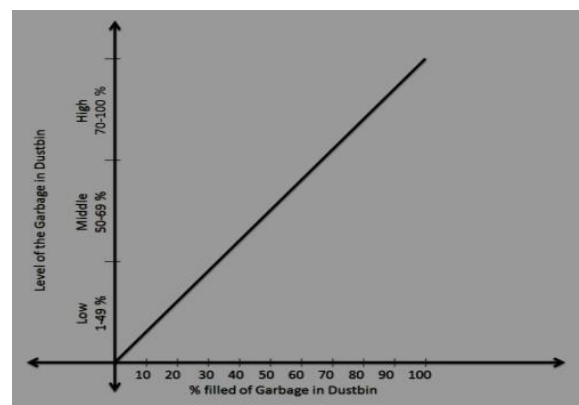

\section{REFFERENCES}

1. Shashank Shukla and Neeraj Shukla, PhD, "Smart Waste Collection System based on IOT (Internet of Things): A Survey", International Journal of Computer Applications (0975 - 8887) Volume 162 - No 3, March 2017.

2. S.S.Navghane, M.S.Killedar and Dr.V.M.Rohokale, "IOT Based Smart Garbage and Waste Collection Bin", ISSN: 2278 - 909X, International Journal of Advanced Research in Electronics and Communication Engineering (IJARECE), Volume 5, Issue 5, May 2016.

3. Somu Dhana Satyamanikanta and M.Narayanan, "smart garbage monitoring system using sensors with rfid over internet of things",Journal of Advanced Research in Dynamical and Control Systems Vol. 9. SP-6/2017.

4. C. Y. Lin, M. Wu, J. A. Bloom, I. J. Cox, and M. Miller, "Rotation, scale, and translation resilient public watermarking for images," IEEE Trans. Image Process., vol. 10, no. 5, pp. 767-782, May 2001.

5. Dr.Sandeep M. Chawarel, Shriram Dighe Akshay Joshi ,Namrata Dajare and Rohini Korke, "Smart Garbage Monitoring System Using Internet of Things", International Journal of Innovative Research in Electrical, Electronics, Instrumentation and Control Engineering ISO 3297:2007 Certified Vol. 5, Issue 1, January 2007, ISSN(online) 2321-2004 ISSN(print) 2321-5526.

\section{AUTHORS PROFILE}

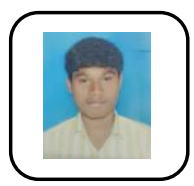

Sk,Khaja Mastan currently I am perusing Final year ECE at Saveetha School of Engineering, Achieved A1 grade in Business English Certificate, Researched about Solar panel Preparation for three months, Attended internship in BSNL based on networking, attended many workshops on IOT, good problem solving skills and able to concentrate on only one task at single Time, Having interest to know about new things in daily life and I am able to speak, read and write Telugu, Hindi, English. And finally I have interest to invite any new electronic gadget which costs less but applications are more than present generation which reasonable cost to all people.

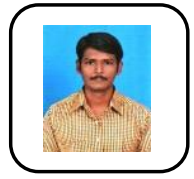

M.RAJA Currently working as Assistant professor at Saveetha School of Engineering, currently I am perusing my PHD at Saveetha University, I completed ME in applied Electronics from ST Peters university, I published more than five journals till now in my career, 10 years of Teaching experience, I was one among the exam cell coordinator in ECE department, I worked for IQAC criteria-II, Student affairs for our department and finally four FDPs attended in our college, I can able to handle Analog circuits, Integrated circuits, satellite communication and Internet working media for engineering students in my department. I will show interest in learning new things.

\section{Published By:}

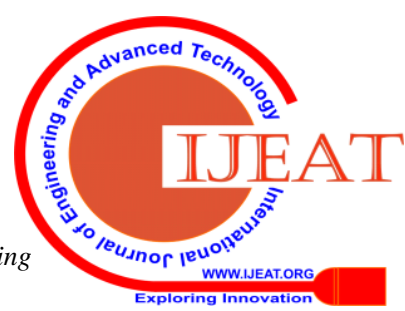

